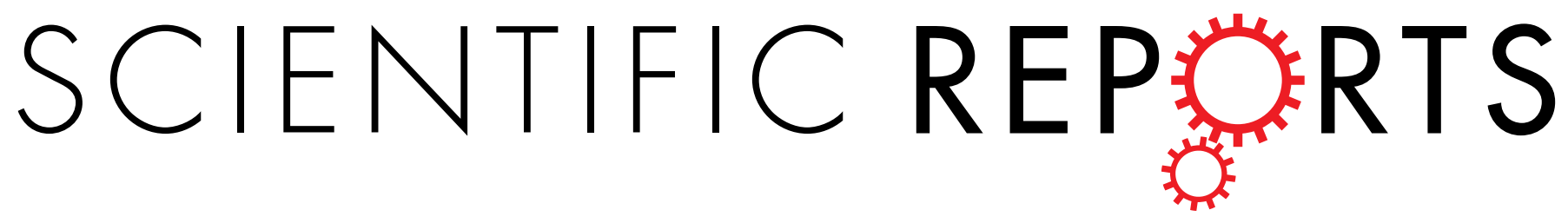

Received: 11 January 2017

Accepted: 9 October 2017

Published: 2 November 2017

\section{Character-based DNA barcoding for authentication and conservation of IUCN Red listed threatened species of genus Decalepis (Apocynaceae)}

Priyanka Mishra $\mathbb{1}^{1}$, Amit Kumar ${ }^{1}$, Gokul Sivaraman ${ }^{1}$, Ashutosh K. Shukla², Ravikumar Kaliamoorthy ${ }^{3}$, Adrian Slater $\mathbb{1}^{4}{ }^{4}$ \& Sundaresan Velusamy ${ }^{1}$

The steno-endemic species of genus Decalepis are highly threatened by destructive wild harvesting. The medicinally important fleshy tuberous roots of Decalepis hamiltonii are traded as substitute, to meet the international market demand of Hemidesmus indicus. In addition, the tuberous roots of all three species of Decalepis possess similar exudates and texture, which challenges the ability of conventional techniques alone to perform accurate species authentication. This study was undertaken to generate DNA barcodes that could be utilized in monitoring and curtailing the illegal trade of these endangered species. The DNA barcode reference library was developed in BOLD database platform for candidate barcodes rbcL, matK, psbA-trnH, ITS and ITS2. The average intra-specific variations (0-0.27\%) were less than the distance to nearest neighbour (0.4-11.67\%) with matK and ITS. Anchoring the coding region $r b c L$ in multigene tiered approach, the combination $r b c L+$ matK $+I T S$ yielded $100 \%$ species resolution, using the least number of loci combinations either with PAUP or BLOG methods to support a characterbased approach. Species-specific SNP position $(230 \mathrm{bp})$ in the matK region that is characteristic of $D$. hamiltonii could be used to design specific assays, enhancing its applicability for direct use in CITES enforcement for distinguishing it from $\mathrm{H}$. indicus.

Decalepis arayalpathra (J. Joseph \& V. Chandras.) Venter (Apocynaceae), locally known as Amirthapala, is a steno-endemic species in Eastern and Western ghats of peninsular India, one of the world's eight hottest hotspots of biodiversity ${ }^{1,2}$. Previously recognized as Janakia arayalpathra (J. Joseph \& V. Chandras.) Venter, the synonym D. arayalpathra has now been placed as a monotypic genus along with Utleria salicifolia and Decalepis hamiltonii in the family Periplocaceae Schltr. Taxonomic revisions at the family level recorded D. arayalpathra (J. Joseph \& V. Chandras.) Venter, D. hamiltonii (Wight \& Arn.), and D. salicifolia (Bedd. ex Hook.f.) Venter as the accepted names for the species under the family Apocynaceae $e^{3,4}$, http://www.theplantlist.org. The species are highly endemic and are restricted to dry and moist deciduous forest segments of Tamil Nadu, Kerala and Andhra Pradesh in India (Fig. 1). The plants are distributed in grassy patches of exposed rocky slopes, which grow in clumps without any firm holding (Fig. 1) and are exposed to heavy wind velocity, high temperature and moderately good rainfall throughout most of the year ${ }^{5}$. Species of Decalepis were assessed as a Critically Endangered-Globally (CR-G), Red listed medicinal plant species by the International Union for Conservation of Nature (IUCN) and declared as a species with high conservation concern by the National Biodiversity Authority of India (NBA) ${ }^{6-8}$, http://www.iucnredlist.org/details/50126587/0. The plants are utilized in traditional Indian and Chinese medicine for treatments of disorders related to the digestive system, lungs and circulatory system. The highly aromatic tuberous roots are used for peptic ulcer, stomach-ache, cancer-like afflictions, etc. and as a rejuvenating tonic by the native Kani tribe of Southern Western Ghats with significant gastric antisecretory and antiulcer activities ${ }^{2,9,10}$. Phytochemically, the presence of 2-hydroxy-4-methoxybenzaldehyde (98\%) in the

${ }^{1}$ Plant Biology and Systematics, CSIR - Central Institute of Medicinal and Aromatic Plants, Research Center, Allalsandra, GKVK Post, Bengaluru, 560065, Karnataka, India. ${ }^{2}$ Biotechnology Division, CSIR - Central Institute of Medicinal and Aromatic Plants, P.O. CIMAP, Lucknow, 226015, Uttar Pradesh, India. ${ }^{3}$ School of Conservation, TransDisciplinary University, 74/2, Jarakabande Kaval, Post Attur, Via Yelahanka, Bangalore, 560064, Karnataka, India. ${ }^{4}$ Biomolecular Technology Group, Faculty of Health and Life Sciences, De Montfort University, Leicester, LE1 $9 \mathrm{BH}, \mathrm{UK}$. Correspondence and requests for materials should be addressed to V.S. (email: vsundaresan@cimap.res.in) 


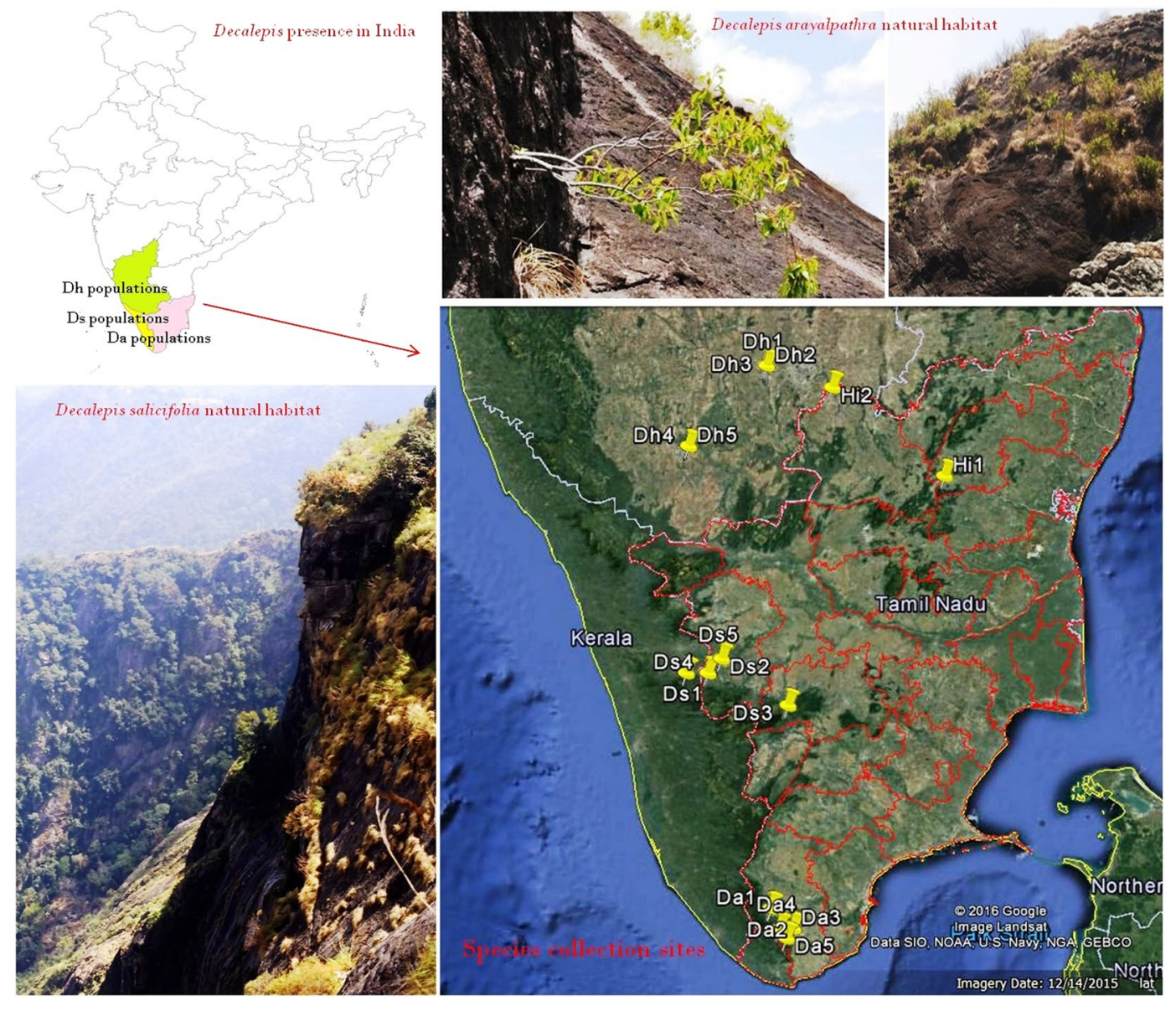

Figure 1. Geographical mapping of Decalepis species in India. Maps were generated through tools in Google Earth program version 7.1.7.2606 (https://www.neowin.net/news/google-earth-pro-7172606) based on the recorded GPS (Garmin) coordinates on the collection sites.

tuberous root oil of $D$. arayalpathra renders it as a valuable source for the production of commercially important flavour compound vanillin ${ }^{11}$. The presence of similar aroma reported in the roots of $D$. hamiltonii and $D$. salicifolia along with their exudation and texture (Fig. S1a-f) place them as a potential substitute in markets for $D$. arayalpathra.

H. indicus is a well-known drug in Ayurvedic and Unani systems of medicine. The plant possesses potential anti-cancerous, immunomodulatory, anti-ulcer, antioxidant, hepatoprotective, anti-inflammatory, antihyperglycemic, anti-diarrhoeal, anti-venom and antimicrobial properties ${ }^{12,13}$. The commercially important plant part used therapeutically is the root, which finds extensive use as a blood purifier, tonic, diuretic and diaphoretic by the tribals of India ${ }^{14}$. The roots of $H$. indicus are very thin and short, and are firmly attached to the soil (Fig. S1h), which requires extensive labour and time to dig out from the ground while those of D. hamiltonii are large, fleshy and loosely attached to the soil (Fig. S1d-f) and are therefore widely used as a substitute by the Indian drug industries for the preparation of the Ayurvedic formulation Sariba (Indian Sarsaparilla), whose botanical identity is $H$. indicus. In order to meet the high global market demand of Hemidesmus roots, the healthy and fleshy tuberous roots of $D$. hamiltonii are traded as a substitute in thousands of tonnes every year from the uncultivated wild sources ${ }^{7,15}$. The indiscriminate collection from the wild has put tremendous pressure on the species survival. Thus, proper identification and authentication of these plants are needed for their sustained use, especially for the threatened species, whose trade is regulated by Convention on International Trade of Endangered Species (CITES).

In our recent study to evaluate genetic diversity and population structure in the wild populations of $D$. arayalpathra based on demographic study and genetic data realized through marker assays, we demonstrated the occurrence of low genetic diversity and high genetic differentiation between the populations ${ }^{16}$. In addition, the populations were recorded to have restricted distribution and high fragmentation and were found to be over-exploited by destructive harvesting. Niche specificity, damage by fruit wasp, population bottleneck, restricted gene flow, and root rot by fungus are the various factors, which have endangered this group in their wild habitat ${ }^{16,17}$. This signals the need for taxon recognition in biodiversity hotspots, which is a key factor for the enforcement of plant protection regulations and the future conservation of the species ${ }^{18}$.

The conservation and management of critically endangered and threatened species primarily focus on the correct identification and delimitation of the target species, thereby improving the status of global biodiversity through the Convention on Biological Diversity $2020^{19}$. Conventional methods to identify raw drugs and 


\begin{tabular}{|l|l|l|l|l|l|}
\hline \multirow{2}{*}{ Parameters assessed } & \multicolumn{6}{|l}{ DNA barcode locus } \\
\cline { 2 - 7 } & $\boldsymbol{r} \boldsymbol{b} \boldsymbol{c L}$ & $\boldsymbol{m a t K}$ & $\boldsymbol{p} \boldsymbol{s} \boldsymbol{b}$ - $\boldsymbol{t r n} \boldsymbol{H}$ & $\boldsymbol{I T S}$ & ITS2 \\
\hline Number of individuals & 17 & 17 & 17 & 17 & 17 \\
\hline PCR Success (\%) & 100 & 100 & 100 & 100 & 100 \\
\hline Sequencing success (\%) & 100 & 100 & 100 & 100 & 100 \\
\hline Sequence length (bp) & 676 & 751 & 376 & $663-666$ & 400 \\
\hline Aligned length (bp) & 676 & 751 & 380 & 679 & 406 \\
\hline No. of variable sites & 12 & 15 & 29 & 94 & 55 \\
\hline No. of indels & 0 & 0 & 0 & 19 & 6 \\
\hline No. of Parsimony informative sites & 11 & 12 & 13 & 80 & 54 \\
\hline Pairwise identity (\%) & 99.4 & 99.3 & 98.2 & 95.8 & 95.5 \\
\hline
\end{tabular}

Table 1. Sequence characteristics of the five DNA barcode loci evaluated in this study.

plant material at the species level are not always feasible due to limitations inherent in morphology-based systems and the dwindling pool of taxonomists ${ }^{20}$. For the last decade, microgenomic identification systems have provided a promising approach towards the diagnosis of biological diversity ${ }^{21}$, with DNA barcoding becoming popular. The diversity among DNA sequences used to identify taxa can be viewed as genetic barcodes ${ }^{22}$. The haploid, uniparentally-inherited mitochondrial region-based single locus DNA barcode COI, in combination with well-developed universal primer sets, resulted in the routine recovery of high-quality sequences from animal clades $^{23}$. Translating these principles into the selection of suitable barcoding region in plants has proved elusive. The plant mitochondrial genome has certain constraints, which precludes its use as a universal plant barcode ${ }^{24}$. The quest shifted towards the plastid and nuclear-based regions, following initial in silico and laboratory-based evaluations of different coding and non-coding markers. The outcome of these trials proposed major individual candidate regions $m a t K, r b c L, r p o B, r p o C 1$, and the intergenic spacers ITS, $p s b A-t r n H$, trnL-F, atpF-atpH and $p s b K-p s b I$, etc. for use in plants based on their discrimination capacity ${ }^{25,26}$. Due to pitfalls and challenges associated with a single locus, the combination of loci emerged as a promising choice to obtain appropriate species discrimination $^{27-29}$. The Consortium for the Barcode of Life (CBOL), proposed $r b c L+$ matK as a standard two-locus barcode for all land plants, but based on further refinement, suggested the need for the addition of supplementary loci, viz. the non-coding cpDNA psbA-trnH intergenic spacer and nuclear ribosomal internal transcribed spacer ( $n r I T S \&$ nrITS2) regions ${ }^{30-33}$.

Hitherto, many researchers have evaluated the combination of several proposed plastid and nuclear regions to envisage the universal barcode in plants through their comprehensive studies in taxonomically complex gro ups $^{24,25,27,29,34-36}$. Currently, the barcoding research is shifting beyond this evaluation phase. Apart from its practical application to provide insights into species-level taxonomy, the technology is being acknowledged as an effective tool by providing pretentious discriminatory power for species in trade (CITES listed), forensic identification, and ecological forensics as well as species identification for rare, threatened and endangered plant groups ${ }^{37-39}$. The potentiality of DNA barcodes to identify the species even from a minute amount of tissue (rather than a whole plant, preferably in flowering stage, as required in the current taxonomic methods) is augmenting the taxonomic tool box by tackling illegal trade of endangered species.

In the absence of a single consensus universal plant barcode, it becomes obligatory to determine the optimal region(s) according to the taxa of interest. The search for a suitable barcode for the genus Decalepis is completely lacking. Therefore, this study was designed to establish the first ever reference library, using the most effective barcode(s) to provide molecular identity to the threatened and endemic species of Decalepis. The efficacy of different analytical approaches of DNA barcoding data will be evaluated to test the discrimination ability of the chosen markers for Decalepis. The findings from this study, in corroboration with the population dynamics proposed in our recently published research ${ }^{16}$, will provide the valuable tools needed to develop a standard protocol to catalogue species identity in CITES enforcement, and to develop conservation plans for the management of threatened species of this group.

\section{Results}

PCR amplification and sequencing success rate. A total of 17 individuals representing all the three species of the genus Decalepis and the species $H$. indicus, were successfully amplified and sequenced using five DNA barcodes $r b c L$, matK, $p s b A$-trnH, ITS and ITS2. The PCR and sequencing success rate for each of the five regions was $100 \%$ with regards to the universality of primers (Table 1). The newly generated 85 sequences were submitted to GenBank (Table 2). Since no barcoding studies have been done to date for the genus Decalepis, we found only two congeneric sequences with accession number KP764847.1 and DQ916845.1 corresponding to D. salicifolia and D. arayalpathra in NCBI BLAST hits. Thus, the database sequences were not included in our analysis. Among the obtained hits, the sequences showed most similarity with other genera of the family Apocynaceae. The PCR amplicons of all the five loci showed a size range consistent with the mean size of the respective marker (Table S1). The sequence characteristics of all the studied barcodes have been tabulated in Table 1. ITS sequences ranged from $663 \mathrm{bp}$ to $666 \mathrm{bp}$ with 94 variable sites and 80 informative sites. The alignment length was $679 \mathrm{bp}$ with 19 indels of $1-3 \mathrm{bp}$ within the aligned region. The primers for ITS used in the study lie in the conserved flanking regions of $18 \mathrm{~S}$ and $26 \mathrm{~S}$, so the sequences were trimmed to the regions of ITS1, 5.8S and ITS2. The ITS2 region also showed 6 indels of $1-2 \mathrm{bp}$ within the aligned region of $406 \mathrm{bp}$. The numbers of variable sites were 55 with 54 informative sites. All the three plastid genes $r b c L$, matK, and $p s b A$-trnH were without indels, with aligned lengths 


\begin{tabular}{|c|c|c|c|c|c|c|c|}
\hline \multirow{2}{*}{$\begin{array}{l}\text { Species (Number } \\
\text { of individuals) }\end{array}$} & \multirow[b]{2}{*}{ Sampling locations } & \multirow{2}{*}{$\begin{array}{l}\text { BOLD } \\
\text { database } \\
\text { sample Id }\end{array}$} & \multicolumn{5}{|c|}{ GenBank accession numbers } \\
\hline & & & $r b c L$ & matK & trnH-psbA & ITS & ITS2 \\
\hline \multirow{5}{*}{$\begin{array}{l}\text { Decalepis } \\
\text { arayalpathra (5) }\end{array}$} & Kuthuraikattimottai; Tirunelveli & CRCBDal & KX528330 & KT273997 & KT362274 & KT338784 & KT362291 \\
\hline & Nadukandanparai; Tirunelveli & CRCBDa2 & KX528333 & KT273998 & KT362275 & KT338785 & KT362292 \\
\hline & Nambikoil, KMTR; Tirunelveli & CRCBDa3 & KX377975 & KT273999 & KT362276 & KT338786 & KT362293 \\
\hline & Maramalai; Kanyakumari & CRCBDa4 & KX528332 & KT274000 & KT362277 & KT338787 & KT362294 \\
\hline & Asambu; Kanyakumari & CRCBDa5 & KX528331 & KT274001 & KT362278 & KT338788 & KT362295 \\
\hline \multirow{5}{*}{$\begin{array}{l}\text { Decalepis } \\
\text { hamiltonii (5) }\end{array}$} & Savandurga; Bangalore Rural & CRCBDh1 & KX618637 & KT279711 & KT362279 & KT338789 & KT362296 \\
\hline & Savandurga; Bangalore Rural & CRCBDh2 & KX643354 & KT279712 & KT362280 & KT338790 & KT362297 \\
\hline & \begin{tabular}{|l|} 
Savandurga; Bangalore Rural \\
\end{tabular} & CRCBDh3 & KX643355 & KT279713 & KT362281 & KT338791 & KT362298 \\
\hline & Chamundi hills; Mysore & CRCBDh4 & KX643356 & KT279714 & KT362282 & KY072831 & KT362299 \\
\hline & Chamundi hills; Mysore & CRCBDh5 & KX809592 & KT279715 & KT362283 & KT338792 & KT362300 \\
\hline \multirow{5}{*}{$\begin{array}{l}\text { Decalepis } \\
\text { salicifolia (5) }\end{array}$} & Topslip; Coimbatore & CRCBDs1 & KX668215 & KT279722 & KT362284 & KT338793 & KT362301 \\
\hline & Kathadimudi Peak; Coimbatore & CRCBDs2 & KX668216 & KT279723 & KT362285 & KT338799 & KT362302 \\
\hline & Vattakandal Shola; Kodaikanal & CRCBDs3 & KX668217 & KT279724 & KT362286 & KT338798 & KY072830 \\
\hline & Topslip; Coimbatore & CRCBDs4 & KX668218 & KT279725 & KT362287 & KT338794 & KT362303 \\
\hline & Kathadimudi Peak; Coimbatore & CRCBDs5 & KX809593 & KT279726 & KT362288 & KT338795 & KT362304 \\
\hline \multirow{2}{*}{$\begin{array}{l}\text { Hemidesmus } \\
\text { indicus (2) }\end{array}$} & Valasamalai; Tiruvannamalai & CRCBHil & KX711546 & KT279727 & KT362289 & KT338796 & KT362305 \\
\hline & Hosur; Krishnagiri & CRCBHi2 & KX711547 & KT279728 & KT362290 & KT338797 & KT362306 \\
\hline
\end{tabular}

Table 2. Taxon sampling, BOLD database details and GenBank accession numbers of the reference library for Decalepis species generated in this study.

of $676 \mathrm{bp}, 751 \mathrm{bp}$ and $380 \mathrm{bp}$, respectively. The coding region $r b c L$ was found to be highly conserved (from $416 \mathrm{bp}$ to $642 \mathrm{bp}$ ) within the species of Decalepis, resulting in 664 conserved sites among the $676 \mathrm{bp}$ aligned region.

Distance analysis and barcoding regions for species identification. Barcode gap analysis provides the distribution of distances within conspecifics and the distance to the nearest neighbour (NN) of each species. The analysis of the distance to the nearest non-conspecific against the distance to the furthest conspecific among the corresponding sequences, based on the K2P genetic distance method, revealed that the mean intra-specific distances were less than the distance to the nearest neighbour, in the cases of matK, ITS and ITS2 loci (Table S2). These three candidate barcodes demonstrated the existence of a clear barcode gap, which is ideal for species identification (Fig. 2). On the other hand, $r b c L$ and $p s b A$-trnH exhibited maximum intra-specific divergence of $1.34 \%$ and $4.11 \%$, respectively among the individuals of $D$. salicifolia. Among the individuals of D. arayalpathra, the highest distance of $1.62 \%$ was recorded with $p s b A-t r n H$. D. hamiltonii, H. indicus, and D. salicifolia shared the maximum identity in terms of their nearest neighbour. D. hamiltonii and $H$. indicus recorded the lowest NN distance of $0.4 \%$ (matK) amongst the four species, which makes $D$. hamiltonii a potent substitute for $H$. indicus in the market. The nuclear region ITS and ITS2 showed maximum inter-specific distances (1.37\% to $11.67 \%)$ among all the 4 species, revealing them to be potent loci, along with $m a t K$, to discriminate the species of genus Decalepis. On the other hand, the coding region $r b c L$ showed only $0-0.15 \%$ divergence with any of the nearest neighbours among D. arayalpathra, D. hamiltonii, D. salicifolia and H. indicus (Table S2). Figure 2 depicts the scatter plot of the maximum intra-specific distances against the NN distances to confirm the existence and magnitude of the barcode gap with all the five candidate barcodes. Maximum intra-specific distances were less than $2 \%$ in all species except D. salicifolia (4.11\%) and H. indicus (2.15\%).

Based on the utility of individual loci, matK, ITS and ITS2 were the favourable choices in the genus Decalepis and the regions were combined with other loci to assess their resolution rate. Table S3 presents the details of the obtained range of inter and intra-specific distances with all the possible combinations of various loci. From among the 26 combinations undertaken in the study, most of them showed the clear presence of a barcoding gap, which reflects the adequacy of the multilocus approach in plant DNA barcoding. The core barcode $r b c L+$ matK showed a slight overlap of between $0.0-0.1 \%$ among the individuals of the species with their nearest neighbour (Fig. S2). However, complementing the barcode with the non-coding locus ITS at the third position improved the resolution with its nearest neighbour, with a clear barcoding gap (Figs 3 and S2). All the possible combinations of matK, ITS and ITS2 showed no intra-specific divergence among the individuals based on pairwise genetic distances and their frequency distribution (Fig. S2). The lowest average intra-specific distance $[0.000$ $( \pm 0.000)-0.013( \pm 0.003) \%]$ and highest average inter-specific distance $[0.019( \pm 0.004)-0.128( \pm 0.011) \%]$ was observed with the combination of ITS + ITS2. Complementing them with the plastid locus matK resulted in a range of $0.000( \pm 0.000)-0.007( \pm 0.001) \%$ intra-specific distances and $0.014( \pm 0.003)-0.074( \pm 0.007) \% \mathrm{NN}$ distance (Table S3). The combinations of matK+ITS + ITS2 and $r b c L+$ matK + ITS loci shared $97.2 \%$ and $98.2 \%$ pairwise identity among their residues. Based on the observations of genetic distances among the species, the core barcode $r b c L+m a t K$ along with the addition of ITS at third position, and the combination of matK + ITS + ITS 2 would both be favourable choices for barcoding the endangered plant species of Decalepis. Though most of the other loci combinations resulted in the presence of a significant barcoding gap with high genetic distances with their nearest neighbour, they also recorded an intra-specific bias among the individuals. 

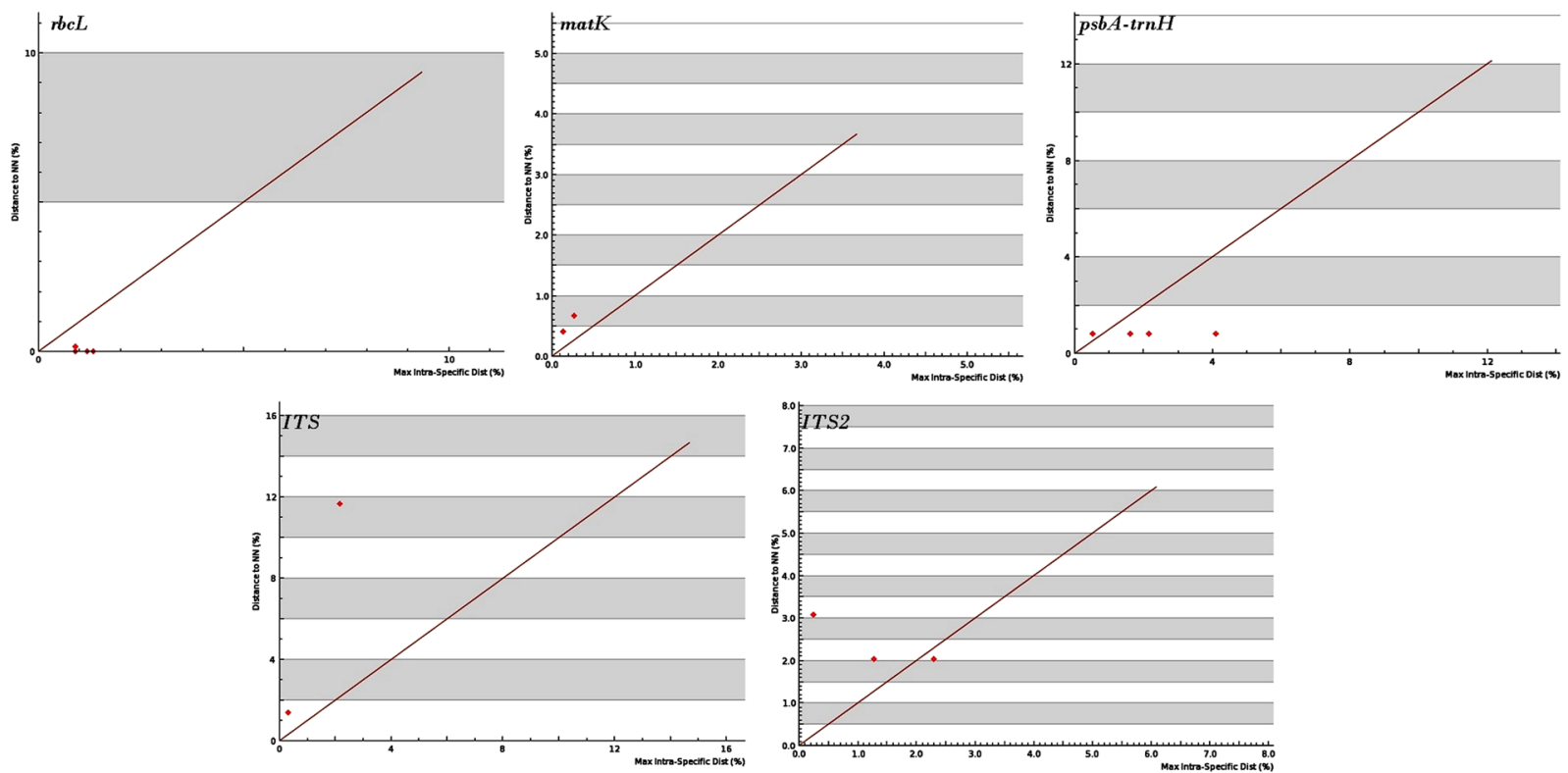

Figure 2. Barcode gap plot for the five individual barcodes. The distances to the nearest neighbor (NN) vs. the maximum intra-specific distances (\%) realized through Kimura-2-parameter (K2P) were plotted for species discrimination. Each dot represents one or several individuals since they share identical values of intra-specific and inter-specific distances. Dots above the 1:1 line indicated the presence of a barcode gap.
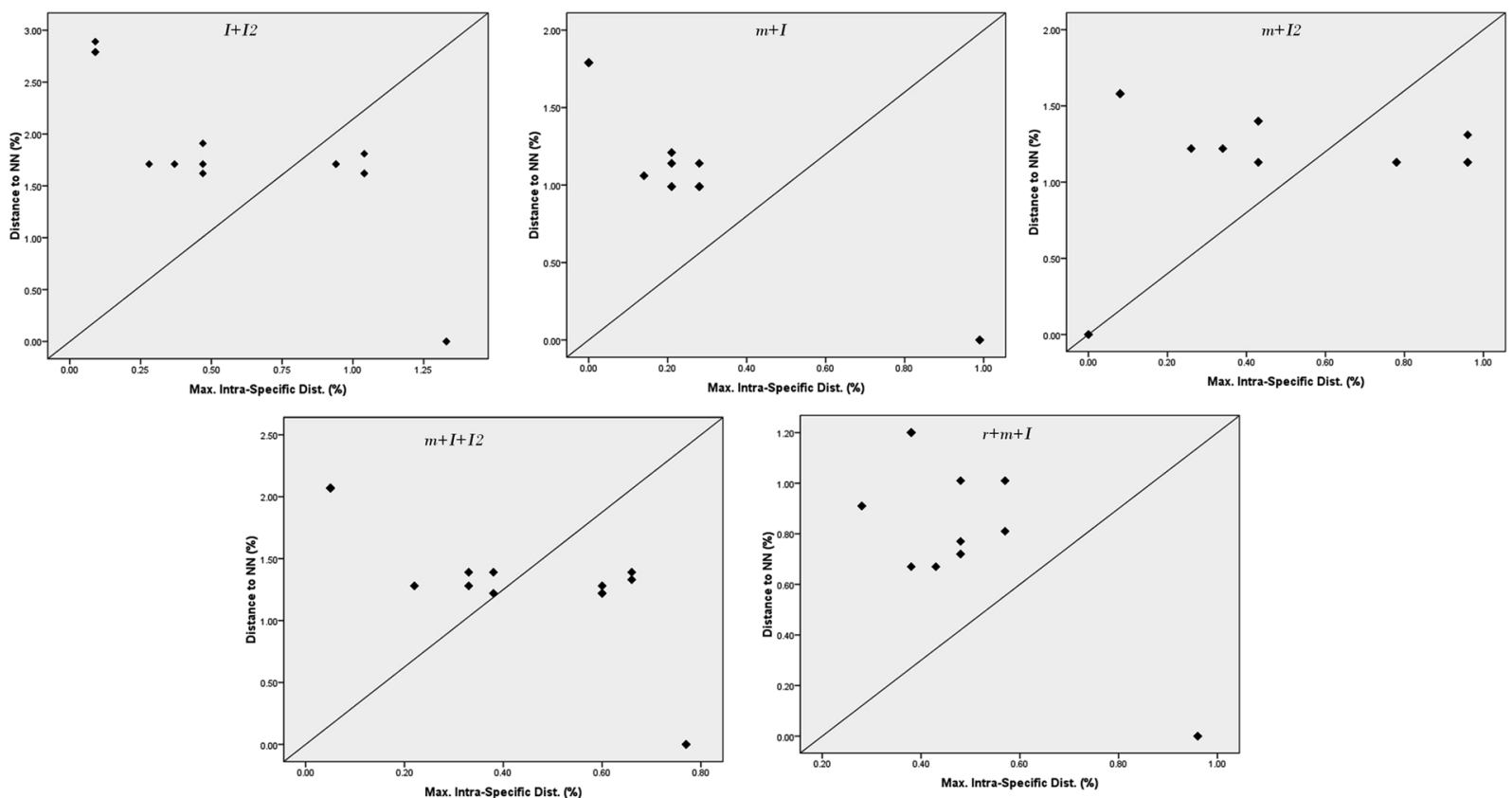

Figure 3. Evaluation of barcode gaps for the favourable barcode combinations in Decalepis species. Distances to the nearest neighbor $(\mathrm{NN})$ were plotted against maximum intra-specific Kimura-2-parameter (K2P) distances (\%). Each dot represents one or several individuals since they share identical values of intra-specific and interspecific distances. Dots above the 1:1 line indicated the presence of a barcode gap.

Phylogenetic analysis of Decalepis species based on parsimony method. For estimating the evolutionary divergences among the species of genus Decalepis, we employed distance-based (NJ) and character-based (MP) methods on all the barcode regions. The results of the criterion-based approach outperformed the distance-based NJ method in assigning individual characters to the tree. Since the characters are reduced to distances in the NJ methods, which sometimes get lost in the pairwise comparisons and result in biased distances, further analyses were carried out using the MP model in PAUP. 


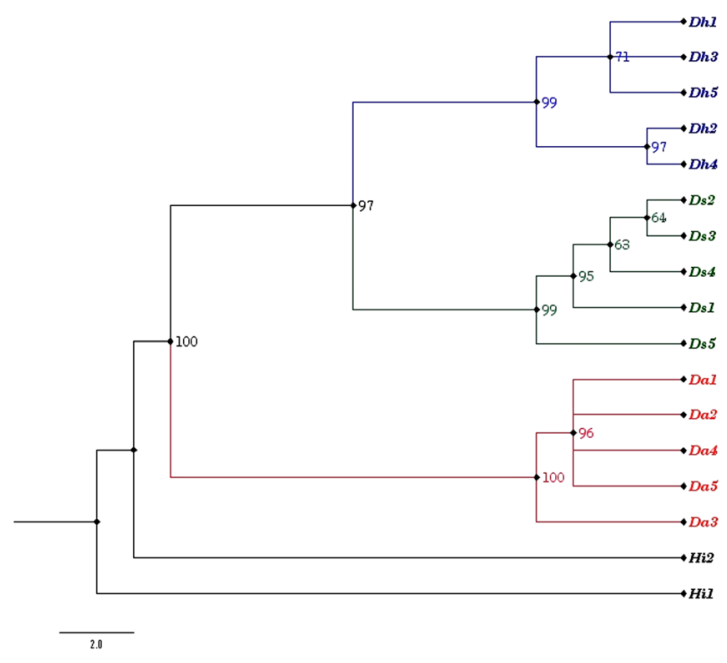

Figure 4. Strict consensus tree showing the relationship of Decalepis species resulting from maximum parsimony analysis using the barcode $r b c L+$ mat $K+I T S$. Tree length $=146, \mathrm{CI}=85 \%, \mathrm{RI}=91, \mathrm{RC}=78 \%$. Bootstrap support values below $60 \%$ are not shown. Individuals corresponding to species monophyly: Red: $D$. arayalpathra, Green: D. salicifolia, Blue: D. hamiltonii.

The evaluation of each barcode locus and combination of loci based on computational phylogenetics, showed similar tree topologies, in agreement with the barcoding gap analysis. The heuristic search of the set of taxa presented a reticulated hypothesis based on the underlying algorithms with reliable clade support. The most favourable barcode dataset $r b c L+m a t K+I T S$ and matK + ITS + ITS2 showed a consistency index (CI) of $85 \%$ $(\mathrm{CI}=0.8562)$ and $90 \%(\mathrm{CI}=0.9024)$ respectively, with the cladogram. The former dataset for parsimony analysis included 2106 characters, of which 103 were parsimony informative and 18 variable characters were found to be parsimony-uninformative, while the latter dataset contributed 146 informative characters from among 1836 total characters. Thus, the combination of coding and non-coding regions, $r b c L$, mat $K$ and ITS, were concluded to be the best choice for species resolution in genus Decalepis (Fig. 4). The strict consensus tree of $r b c L+m a t K+I T S$ resulted in a tree length of 146 steps with the node supported clade framing the well resolved species of Decalepis. The retention index (RI) was 0.9121 and the re-scaled consistency index (RC) was 0.7809 . The individuals belonging to $D$. arayalpathra showed several polytomies, which makes the intra-specific relationship difficult. However, they formed a clade, which was $100 \%$ supported, with D. hamiltonii, D. salicifolia as sister species. At the large polytomy, $D$. hamiltonii and $D$. salicifolia framed two well supported groups with a $97 \%$ bootstrap value. The resulting tree maintained the species monophyly in terms of the Decalepis species, and both individuals of $H$. indicus framed the nodal cluster at the base of the tree (Fig. 4).

Comparison of discrimination methods and barcode regions. The discrimination ability of the all the five candidate barcodes and their 26 possible combinations were compared using TaxonDNA and BLOG. All the barcoding datasets represented equal number of individuals corresponding to respective species. The rates of "correctly identified", "misidentified" and "not identified" individuals for each dataset and method are shown in Table 3. Averaged over both methods, matK (100\%), ITS (75-100\%) and ITS2 (100\%) turned out to have the highest success rate among the single locus barcode. The combinations of loci that included all three of these regions provided higher success rates than other combination barcodes. The best two locus combinations ranged in the order matK + ITS $2(100 / 100 / 88.23 \%)>$ mat $K+I T S(100+88.23+88.23 \%)>I T S+I T S 2$ $(100+88.23+88.23 \%)$, based on the BM, BCM and All Species Barcode modules of TaxonDNA. When we compared these loci based on a character-based approach, the combinations proved to be highly successful, reaching 75-100\% correct identification for the species using BLOG (Table 3). The $r b c L$ region showed very poor discrimination success for single and two-locus barcodes. However, supplementing it with the other loci, with $r b c L$ being at the first position, afforded $100 \%$ correct identification (100/0/0), using either the TaxonDNA or BLOG based methods. Thus, a tiered approach to barcoding promised the potential to barcode the endangered species of genus Decalepis.

Based on the comparison of methods, both the TaxonDNA and BLOG approaches performed equally well on average across all the favourable barcodes (both provided $75-100 \%$ correct identification). However, the rate of misidentification for all the loci was $0 \%$ in TaxonDNA but $25 \%$ in BLOG (Table 3, highlighted in grey). In contrast, BLOG outperformed TaxonDNA by resulting $0 \%$ individuals as "not identified", whereas $11.76 \%$ of individuals were not identified in TaxonDNA. Phylogenetic analysis of Decalepis species based on a character-based approach also resulted in assigning individual characters to the tree. Thus, character-based rather than distance-based methods are the appropriate choice to test the hypothesis. 


\begin{tabular}{|c|c|c|c|}
\hline \multirow[b]{2}{*}{ Barcode locus/loci } & \multicolumn{2}{|l|}{ TaxonDNA } & \multirow[b]{2}{*}{ BLOG } \\
\hline & Best match (\%) & Best close match (\%) & \\
\hline$r b c L$ & $18 / 23 / 59$ & $18 / 23 / 58$ & $0 / 25 / 75$ \\
\hline matK & $100 / 0 / 0$ & $88 / 0 / 12$ & $100 / 0 / 0$ \\
\hline psbA-trnH & $94 / 6 / 0$ & $94 / 6 / 0$ & $100 / 0 / 0$ \\
\hline ITS & $100 / 0 / 0$ & $88 / 0 / 12$ & $75 / 25 / 0$ \\
\hline ITS2 & $100 / 0 / 0$ & $100 / 0 / 0$ & $100 / 0 / 0$ \\
\hline$r b c L+m a t K$ & $82 / 12 / 6$ & $83 / 12 / 6$ & $100 / 0 / 0$ \\
\hline$r b c L+p s b A-t r n H$ & $76 / 24 / 0$ & $76 / 24 / 0$ & $100 / 0 / 0$ \\
\hline$r b c L+I T S$ & $100 / 0 / 0$ & $88 / 0 / 12$ & $75 / 25 / 0$ \\
\hline$r b c L+I T S 2$ & $100 / 0 / 0$ & $100 / 0 / 0$ & $75 / 0 / 25$ \\
\hline$m a t K+p s b A-t r n H$ & $100 / 0 / 0$ & $76 / 24 / 0$ & $75 / 25 / 0$ \\
\hline mat $K+I T S$ & $100 / 0 / 0$ & $88 / 0 / 12$ & $100 / 0 / 0$ \\
\hline$m a t K+I T S 2$ & $100 / 0 / 0$ & $100 / 0 / 0$ & $75 / 0 / 25$ \\
\hline psbA-trnH+ITS & $82 / 12 / 6$ & $83 / 12 / 6$ & $75 / 0 / 25$ \\
\hline psbA-trnH+ITS2 & $76 / 24 / 0$ & $76 / 24 / 0$ & $75 / 0 / 25$ \\
\hline$I T S+I T S 2$ & $100 / 0 / 0$ & $88 / 0 / 12$ & $75 / 25 / 0$ \\
\hline$r b c L+m a t K+p s b A-t r n H$ & $100 / 0 / 0$ & $88 / 0 / 12$ & $100 / 0 / 0$ \\
\hline$r b c L+m a t K+I T S$ & $100 / 0 / 0$ & $100 / 0 / 0$ & $100 / 0 / 0$ \\
\hline$r b c L+m a t K+I T S 2$ & $100 / 0 / 0$ & $100 / 0 / 0$ & $75 / 0 / 25$ \\
\hline$r b c L+p s b A-t r n H+I T S$ & $100 / 0 / 0$ & $88 / 0 / 12$ & $100 / 0 / 0$ \\
\hline$r b c L+p s b A-\operatorname{trn} H+I T S 2$ & $100 / 0 / 0$ & $100 / 0 / 0$ & $75 / 0 / 25$ \\
\hline$r b c L+I T S+I T S 2$ & $100 / 0 / 0$ & $88 / 0 / 12$ & $75 / 25 / 0$ \\
\hline$m a t K+p s b A-t r n H+I T S$ & $100 / 0 / 0$ & $100 / 0 / 0$ & $100 / 0 / 0$ \\
\hline$m a t K+p s b A-t r n H+I T S 2$ & $100 / 0 / 0$ & $100 / 0 / 0$ & $75 / 0 / 25$ \\
\hline$m a t K+I T S+I T S 2$ & $100 / 0 / 0$ & $88 / 0 / 12$ & $100 / 0 / 0$ \\
\hline psbA-trnH+ITS + ITS2 & $100 / 0 / 0$ & $100 / 0 / 0$ & $100 / 0 / 0$ \\
\hline$r b c L+m a t K+p s b A-t r n H+I T S$ & $100 / 0 / 0$ & $88 / 0 / 12$ & $100 / 0 / 0$ \\
\hline$r b c L+m a t K+p s b A-t r n H+I T S 2$ & $100 / 0 / 0$ & $100 / 0 / 0$ & $75 / 0 / 25$ \\
\hline$r b c L+p s b A-t r n H+I T S+I T S 2$ & $100 / 0 / 0$ & $100 / 0 / 0$ & $100 / 0 / 0$ \\
\hline$r b c L+m a t K+I T S+I T S 2$ & $100 / 0 / 0$ & $100 / 0 / 0$ & $75 / 0 / 25$ \\
\hline$m a t K+p s b A-t r n H+I T S+I T S 2$ & $100 / 0 / 0$ & $100 / 0 / 0$ & $100 / 0 / 0$ \\
\hline$r b c L+m a t K+p s b A-t r n H+I T S+I T S 2$ & $100 / 0 / 0$ & $100 / 0 / 0$ & $100 / 0 / 0$ \\
\hline
\end{tabular}

Table 3. Species identification rates in \% (correctly identified/misidentified/not identified) using two different classification methods for each of the five barcodes and their combinations. TaxonDNA: Best match and Best close match results. Not identified rates are summed over the "Ambiguous" and "No match" categories. Please see supplementary Table S4 for details. BLOG: percentage correct classification for test file, using 90\% slicing at species level (Refer to materials and methods for detailed analysis). The highest success rate for preferred barcoding options in Decalepis are highlighted in grey.

\section{Discussion}

The efficiency of barcoding regions in elucidating the molecular identity of Decalepis species. The present study is the first published attempt to describe the molecular phylogeny of the threatened and endangered species of Decalepis. It shows that barcoding markers can accurately distinguish between the species, revealing homogeneous clades with high resolution assignment of individuals at the species level (Fig. 4). From among the tested plastid and nuclear loci, ITS had the highest efficiency as a single locus in the identification of species in Decalepis (Fig. S3). The high copy number of $r R N A$ genes, greater discriminatory power at low taxonomic levels and higher evolutionary rate makes ITS a promising locus in plant molecular systematics ${ }^{40}$. The better phylogenetic signalling of ITS compared to the plastid barcoding markers in Decalepis is compatible with the results of other genus-level studies in Passiflora ${ }^{41}$, Euphorbia ${ }^{42}$, Paeonia $^{43}$ and Melilotus ${ }^{44}$, amongst others.

The two barcodes $r b c L$ and $p s b A$-trnH had the lowest discriminatory power as a single locus, which limits their utility in Decalepis, despite their value for barcoding of other plant groups ${ }^{20,24}$. Both regions failed to discriminate between the species, and the resulting phylogenetic tree showed huge over-mixing of individuals with poor clade support. The potential substitute, $H$. indicus, grouped with $D$. hamiltonii, and the individuals of $D$. salicifolia were found to be unresolved at the base of the tree (Fig. S3). The problems of alignment ambiguities and frequent inversions associated with palindromic sequences within the $p s b A$-trn $H$ region have been found in multiple lineages of Angiosperms and possibly complicate its use as a barcode, especially if they occur within species $^{29}$. The suitability of the chloroplast region $r b c L$ for studies of molecular evolution at the species level has been controversial, in part due to its $\sim 1430 \mathrm{bp}$ length. For clear species discrimination, the entire region needs to be sequenced, which limits its use as a barcoding sequence. The ideal barcoding region should be short enough 
to amplify, and amenable to analysis through single-pass sequencing ${ }^{35}$. However, complementing the region with other barcoding marker(s) improves its discrimination ability, as shown in earlier studies ${ }^{29,31,35,45}$.

The chloroplast mat $K$ coding region presented a better credentials as a candidate barcode, showing both high sequence recovery and high identification rates either as a single locus or in combination with ITS. The $m a t K+I T S$ combination framed the entire sister species of Decalepis as a major cluster, with $H$. indicus positioned as an out-group at a nodal branch at the base of the tree (Fig. 4). The chloroplast gene matK showed a higher rate of nucleotide substitutions than other tested loci from the plastid genome, which provided higher inter-specific divergence values among matK sequences. The nuclear two-locus barcode combination of ITS + ITS2 also showed a closely similar result, which confirms the advantage of the multi-locus consensus barcode approach in plant DNA barcoding.

In the effort to develop molecular identification methods for the species of Decalepis for the purpose of CITES control, the focus is to provide a clear resolution of sister species and of potential substitutes. The search for a universal DNA barcode for plants led to the recommendation by CBOL of the combination two-locus barcode $r b c L+m a t K^{29}$. In this study, we have performed a comprehensive evaluation of all the 26 possible (single, twoand three-locus) combinations of the two recommended barcodes plus three supplementary candidate regions. Amongst all the three locus barcode combinations investigated here, $r b c L+$ mat $K+I T S$ provided the best identification in maintaining the species monophyly in Decalepis (Fig. 4). Most importantly, the closely related species that were prone to substitution or adulteration, such as $D$. hamiltonii and $H$. indicus, could be accurately identified by the combination barcode $r b c L+$ matK + ITS. In particular, the rapidly evolving non-coding nuclear region ITS plays a valuable role in anchoring the universal standard coding regions $r b c L$ and $m a t K$ in a multigene tiered approach. This choice may vary among the groups under investigation. However, we found that the molecular phylogeny corresponded well with the latest morphological revisions in genus Decalepis ${ }^{3,4}$ and thus could be complemented with morphology to provide accurate identification of the species.

Feasibility of analytical methods to provide clear discrimination of Decalepis species. An adequate bioinformatics resource to support the barcoding of life goes in parallel with finding a standard barcoding system for plants that goes beyond those relating to the use of a single marker $(C O I)$ for animal barcoding. Huge and overlapping datasets along with alignment difficulties of non-coding regions in plants necessitate the development of the best data analysis tools. Hitherto, different analytical methods have been employed for the assessment of species discrimination ability in plants group, with all of them showing certain pros and cons with the same dataset ${ }^{46-50}$. The two widely implemented approaches of distance- (TaxonDNA and NJ) and character-based methods (BLOG and PAUP), tested in this study both gave the highest correct identification rates. Our result seems to support the character-based approach as a highly workable and accurate method by producing a set of rules to characterize each species in terms of nucleotides at particular positions. For example, if position $548=\mathrm{T}$ and position $554=\mathrm{A}$ (as obtained in $r b c L+m a t K+I T S$ ), then the specimen is classified as $D$. arayalpathra. Also, there was $100 \%$ identification through BLOG for all the favourable loci, while TaxonDNA produced a few unidentified individuals (Table 3).

Among the three different modules ("BM", "BCM", and "All Species Barcodes") implemented in TaxonDNA, the combination barcode $r b c L+$ mat $K+I T S$, correctly identified 15 species $\sim 88.23 \%$ through "All Species Barcodes". The "All Species Barcodes" criterion is known to be the strictest in providing correct identification as it requires query sequence matches to be above the proposed threshold ${ }^{51}$. The correct identification was $100 \%$ either through the BM, BCM and BLOG-based analysis among the Decalepis species. In order to assess the evolutionary process underlying the sequence datasets from the Decalepis group, MP analysis based on optimal criteria appeared to be the more reliable method, which produced several possible trees with correct topologies. The clustering algorithm used in the NJ method, which assumes K2P genetic distances between the sequences, might obscure ambiguities in data since it produces only one final tree ${ }^{52}$. The datasets used in the study, are ideal for these methods, as the sampled number of individuals per species was optimal, preventing the potential bias for all the methods. Overall, the results obtained in the study support the character-based approaches, BLOG and PAUP, as the method of choice in identifying the critically endangered species of genus Decalepis. The results of BLOG to characterize each species in terms of nucleotides at particular positions could be valuable in designing species-specific assays in CITES enforcement.

Application of barcoding tools in conservation of Decalepis. Phylogenetic diversity defined by DNA barcode sequence data within and across the ecological communities at varying geographic scales can be an important measure in defining species boundaries and documenting new species, which in turn may result in the identification of targeted habitats for conservation ${ }^{53}$. Use of DNA barcoding to effectively discriminate threatened species to support the ongoing conservation measures has been successfully evaluated in many plant groups ${ }^{42}$. In the present study, we found that the combined barcode marker $r b c L+$ mat $K+I T S$ supported a reticulated hypothesis of species in Decalepis, identifying it as a monophyletic group in accordance with previous studes ${ }^{3,4}$. As mentioned earlier, in the taxon sampling section of the manuscript, the individuals of $D$. arayalpathra were sampled from the population of regions Tirunelveli (Da1, Da2, Da3) and Kanyakumari districts (Da4, Da5), which showed a slightly higher level of genetic variation, resulting in a high priority for conservation concerns in our recent study of the population dynamics of $D$. arayalpathra ${ }^{16}$. Through DNA barcoding, it was interesting to conclude that the combined barcode marker $r b c L+$ mat $K+I T S$ represented the genuine identity of the populations by clustering the individuals with $96 \%$ node support respective to their geographic range (Fig. 4). Da3 was placed as a polytomy at the base of the species cluster with an exception, which might be the result of a genetic pool with some migrants and admixed individuals ${ }^{16}$. The barcoding database generated through this study will help in gaining a more accurate assessment of the conservation status of Decalepis species based on molecular gene pools. 
Species- or genus-specific single nucleotide polymorphisms (SNPs) based on chloroplast DNA are well suited for molecular marker development and have been shown to be an ideal source of genetic information that could be useful for species discrimination ${ }^{54}$. Genus- or species-specific assays enhance their applicability for direct use in CITES enforcement ${ }^{55,56}$. The $751 \mathrm{bp}$ amplicons of the best single locus, mat $K$, presented opportunities for species-specific sequence differentiation at different positions in the region between $225 \mathrm{bp}$ to $630 \mathrm{bp}$. The sequences around the SNPs were checked for restriction sites. The most valuable SNP is the cytosine (C) located at position 230 of $D$. hamiltonii sequence which is exchanged by thymine $(\mathrm{T})$ in the remaining species so that the suitable restriction enzyme BstXI can be applied to discriminate between the species. The D. arayalpathra sequence also showed the presence of species-specific SNPs in the matK region at positions 90 and 587, but no suitable restriction sites were found to be available (although it may be possible to design species-specific PCR primers or HRM assays to detect them). Three species-specific SNPs were detected in the D. salicifolia sequence at positions 281, 437 and 627 with suitable restriction sites of $M n 1 \mathrm{I}, H p h \mathrm{I}$ and $A l w \mathrm{I}$, respectively (dx. doi.org/10.5883/DS-CRCB). Thus, the specific sequence positions identified through the barcoding regions used in the present study can be used to design species-specific assays for testing the highly traded species of genus Decalepis.

\section{Conclusion}

This study unequivocally demonstrates the efficiency of DNA barcoding for endemic species identification. The signature sequences of the proposed barcode $r b c L+$ mat $K+I T S$ provided accurate signals in facilitating the molecular identity of Decalepis species in accordance with its latest taxonomic revision. The region clearly framed the entire set of sister species of Decalepis as a major cluster, with its potential substitute $H$. indicus in an out-group positioned as a nodal branch at the base of the tree. The character-based approach through PAUP and BLOG successfully distinguished $100 \%$ of investigated samples, rendering its accuracy and reliability as a method of choice in DNA barcoding studies. The species-specific assays derived from mat $K$ barcoding region sequences, further confirm its value in providing accurate species discrimination method. The inclusion of different conspecific populations is expected to gain insight into the conservation status of Decalepis species hotspots as well as emphasizing the practical application of DNA barcoding as a tool for the biodiversity conservation of endemic and threatened plant groups.

\section{Materials and Methods}

Taxon sampling and ethics statement. Species of genus Decalepis are highly endangered in its wild habitat. For sampling the plant material, an appropriate permission was granted by the Tamil Nadu Biodiversity Board (Letter Ref No. TNBB/52/2011 dated September 28, 2011, for a one year period from December 2011 to November 2012) and the Principal Chief Conservator of Forests and Chief Wildlife Warden, Tamil Nadu Forest Department (Letter Ref. No. WL5/ 23758/2011 dated December 5, 2011, for a one year period from December 2011 to November 2012) to study the reproductive biology, conservation issues, problems in germination, process of multiplication, DNA barcoding studies, etc. In our recent research publication, we performed population dynamics study on a total of sixty individuals corresponding to nine populations from different geographic regions to gain initial insight into their genetic diversity and population structure. It concluded that genetic diversity was remarkably low, but few populations from regions of Tirunelveli and Kanyakumari districts showed a slightly higher level of genetic variation resulting in high priority for conservation concerns ${ }^{16}$. Based on our findings, we considered the sampling of the same population in DNA barcoding studies for D. arayalpathra. Other plant species viz. D. hamiltonii and D. salicifolia were collected from their corresponding geographical hotspots. Plants of $H$. indicus were collected for out-group studies being the potential adulterant for D. arayalpathra.

A total of 15 individuals belonging to three different species of Decalepis were assembled from different geographical regions of Tamil Nadu, Kerala and Karnataka. Two individuals of $H$. indicus were collected from Tamil $\mathrm{Nadu}$ and Karnataka (Fig. 1). The samples were desiccated in silica gel and stored at $-20^{\circ} \mathrm{C}$ prior to DNA extraction. Vouchers specimens for each species sampled in this study were deposited at the herbarium maintained at Foundation for Revitalisation of Local Health Traditions (FRLHT), Bangalore, India and CSIR-Central Institute of Medicinal and Aromatic Plants (CIMAP), Lucknow, India, for future reference and the corresponding details are listed in Table 2.

Molecular methods. Total genomic DNA was isolated from the reference samples using the cetyl trimethyl ammonium bromide $(\mathrm{CTAB})$ protocol ${ }^{57}$. Isolated DNA was checked for its quality and quantity by electrophoresis on a $0.8 \%$ agarose gel and spectrophotometric analysis (NanoDrop, ND-1000, USA), respectively. The DNA was diluted to a final concentration of $\sim 25-50 \mathrm{ng} / \mu \mathrm{l}$ for PCR amplification. Five candidate DNA barcode loci were amplified with the established primers, which included two coding cpDNA loci $r b c L$ and matK; one non-coding cpDNA intergenic spacer loci, psbA-trnH and the nrDNA loci, ITS and ITS2. Details of primers and PCR conditions are listed in Table S1. PCR amplifications for each primer set were carried out in a $50 \mu$ l volume containing 1X Taq DNA polymerase buffer, 200 $\mu \mathrm{M}$ each dNTP (dATP:dTTP:dCTP:dGTP in 1:1:1:1 parts), 5-10 pmol of each primer (forward and reverse), 1 unit of Taq DNA polymerase and $~ 25-50 \mathrm{ng}$ of template DNA. Successful amplicons were analysed by electrophoresis on $2 \%$ agarose gel. Subsequently, products of target molecular weight were purified with a Nucleospin PCR purification kit, using the manufacturer's (MACHEREY-NAGEL - 07/2014, Rev.03) protocol and re-checked through electrophoresis on $2 \%$ agarose gel. The obtained product was subjected to Sanger's di deoxy sequencing reactions, in forward and reverse directions using the BigDye Terminator v3.1 Cycle Sequencing Kit (Applied Biosystems, Foster City, CA) on an ABI 3130 XL genetic analyzer (Applied Biosystems). 
Databasing. Specimen data for each region were deposited in the Barcode of Life Data Systems (BOLD) ${ }^{58}$ (http://www.boldsystems.org) under the project CRCB - "DNA barcoding in Decalepis" (Table 2). All the data are accessible on BOLD under the dataset DS-CRCB (dx.doi.org/10.5883/DS-CRCB). The sequences were submitted to GenBank and are publicly accessible under the accession numbers listed in Table 2.

Data analysis. The electropherograms obtained for each region were base-called using PHRED; sequences assembled and edited using Sequencher (Gene Codes Corporation, Ann Arbor, MI, USA). Finally, the sequences were blasted on NCBI BLAST under the programme BLASTN 2.2.1+ ${ }^{59,60}$ and on to BOLD using Identification Request for checking their homology with other available sequences. All the barcode sequences were greater than $500 \mathrm{bp}$ in length and free from contamination. The edited sequences were then aligned with Muscle 3.8.31 on the EMBLEBI website (http://www.ebi.ac.uk) under default parameters and adjusted manually in BioEdit $\mathrm{v} 7 \cdot 1 \cdot 3.0^{61}$. The sequences were trimmed at both the ends to remove the primer sequences. All the variable sites were rechecked using the original trace files. Alignments can be obtained from the corresponding author upon reasonable request. Five candidate DNA barcode loci and their 26 possible combinations along with multi-gene tiered barcoding approach were evaluated based on the methods described ahead.

Distance-based barcoding gap analyses. The distribution of within-species divergence to between-species divergence for the five candidate barcoding loci were studied using the 'distance summary' tool in BOLD. Using a barcode gap criterion, the intra-specific vs. nearest neighbour (NN) genetic distance was plotted to identify the barcoding gap. For the combinations of loci, the distribution of intra- and inte-rspecific variability was assessed by MEGA version $6^{62}$ using the Kimura two-parameter distance model (K2P) of nucleotide substitution with pairwise deletion of missing sites ${ }^{63}$. Barcoding gaps for all the loci were recorded by plotting the inter- and intra-specific distances with frequency distribution in bin interval of 0.005 ; estimated using the "pairwise summary" in Species Identifier 1.7.7 program from the TaxonDNA software package ${ }^{64}$. Since the coalescent depths vary among species, substantial overlap between intra- and inter-specific distances might not compromise with the species identification success. Therefore, the local barcoding gap for each species was evaluated for all the combinations of barcodes, by plotting the distance to the nearest non-conspecific against the distance to the NN with a 1:1 slope ${ }^{65}$. The proportion of correct species identifications were annotated using "Best Match" (BM), "Best Close Match" (BCM), and "All Species Barcodes" functions embedded in TaxonDNA. The tool examines all the sequences present in the aligned dataset and compares each successive sequence with all the other sequences to determine the closest match. The BM module then classifies the sequences as correct and incorrect based on the indicated pair from the similar species or different species, respectively. While the various equally best matches from different species are referred to as ambiguous, the BCM module works on the intra-species variability criterion and is considered to be the more rigorous method in TaxonDNA.

Character-based approach through BLOG. Barcoding with LOGic (BLOG), is a character-based machine learning approach with program BLOG2.0 to classify specimen's sequences to species, using a set of classification rules in terms of DNA barcode locations of key diagnostic nucleotides ${ }^{66,67}$. It formulates the classification rules based on the supplied training dataset and then applies the same to both the training set and the test set to estimate the identification success. The different barcode datasets used in this study were subjected to $90 \%$ slicing within species-level with a maximum of 500 iterations (GRASPITER $=500$ ) and a maximum time of 5 minutes for analysis (GRASPSECS $=300$ ). The logic formula with lowest false positive rate against the reference dataset was taken as identification basis.

Phylogenetic trees using distance- and character-based methods. To delimit the species into discrete clades or monophyletic groups, phylogenetic analysis was carried out on the studied datasets. The evolutionary process of the sequence data was assessed based on distance-based and character-based methods. Neighbour-joining with minimum evolution (NJ) clustering algorithm was used to calculate the evolutionary distance between sequences. The NJ trees were constructed in PAUP $4.0^{68}$ based on K2P distances as genetic measure and setting negative branch lengths to zero.

Among the character-based approaches, maximum parsimony (MP) method was used to determine the most probable evolutionary event history between sequences. MP analysis was performed in PAUP 4.0 with the HKY-gamma substitution model to account for rate variation among sites. An initial heuristic search was made with 1000 replicates and branch swapping was performed by tree-bisection-reconnection (TBR). A maximum of 10 trees were held at each step with random stepwise addition for the starting tree in each replicate. The trees found in the first round were subjected to a second search by TBR swapping holding up to 15000 trees and swapping to completion. The reliability of the node was assessed by a bootstrap test with 1000 pseudo-replicates ${ }^{69-71}$. $H$. indicus was used as outgroup for all the methods.

Data Accessibility. GenBank (NCBI) [http://www.ncbi.nlm.nih.gov/genbank] Accession numbers for nucleotide sequences are listed in Table 2. Sequence alignments have been archived in BOLD [http://www. boldsystems.org] project DS-CRCB (dx.doi.org/10.5883/DS-CRCB).

\section{References}

1. Myers, N. et al. Biodiversity hotspots for conservation priorities. Nature 403, 853-858 (2000).

2. Sharma, S. \& Shahzad, A. An Overview on Decalepis: A genus of woody medicinal climbers. J. Plant Sci. Res. 1, 104 (2014).

3. Joseph, J. \& Chandrasekaran, V. Janakia arayalpathra - a new genus and species of Periplocaceae from Kerala, South India. Journal of the Indian Botanical Society 57, 308-312 (1978).

4. Venter, H. J. T. \& Verhoven, R. L. A tribal classification of the Periplocoideae (Asclepiadaceae). Taxon 46, 705-720 (1997).

5. Prabakaran, V., Ravikumar, K. \& Vijayasankar, R. Janakia arayalpathra - the quest. Amruth, 5(5) (2001). 
6. Molur, S. \& Walker Report on conservation assessment and management plan (CAMP) workshop for selected species of medicinal plants of southern India. Bangalore 16-18, 108 (1997).

7. Ravikumar, K. \& Ved, D. K. Illustrated field guide to100 red listed medicinal plants of conservation concern in southern India Bangalore: FRLHT (2000)

8. Anonymous. Tamil Nadu State Biodiversity Notification, Ministry of Environment and Forests, New Delhi, India REGD No DL33004/99 (2011).

9. Pushpangadan, P. et al. Amrithapala (Janakia arayalpathra, Joseph and Chandrasekaran), a new drug from the Kani Tribe of Kerala. Anc. Sci. Life. 9, 121 (1990).

10. Shine, V. J., Shyamal, S., Latha, P. G. \& Rajasekharan, S. Gastric antisecretory and antiulcer activities of Decalepis arayalpathra. Pharm. Biol. 45, 210-216 (2007).

11. Verma, R. S. et al. Chemical composition of root aroma of Decalepis arayalpathra (Joseph, J. \& Chandras, V.) Venter, an endemic and endangered ethnomedicinal plant from Western Ghats India. Nat. Prod. Res. 28, 1202-1205 (2014).

12. Austin, A. A review on Indian Sarsaparilla, Hemidesmus indicus (L.) R. Br. J. Biol. Sci. 8, 1-12 (2008).

13. Panchal, G. A., Panchal, S. J. \& Patel, J. A. Hemidesmus indicus: A review. Pharmacologyonline 2, 758-771 (2009).

14. Aparna, B. \& Subha, G. Medicinal importance of Hemidesmus indicus: a review on its utilities from ancient Ayurveda to 20th Century. Adv. Biores. 5, 208-213 (2014)

15. Ved, D. \& Goraya, G. S. Demand and Supply of Medicinal Plants in India, 1st ed. Bangalore, India: NMPB, New Delhi and FRLHT (2007).

16. Mishra, P. et al. Population dynamics and conservation implications of Decalepis arayalpathra (Joseph, J. \& Chandras, V.) Venter. a steno endemic species of Western Ghats, India. Appl. Biochem. Biotechnol. 176, 1413-1430 (2015).

17. Premalatha, K. et al. Molecular profiling of fungal assemblages in the healthy and infected roots of Decalepis arayalpathra (Joseph, J. \& Chandras, V.) Venter, an endemic and endangered ethnomedicinal plant from Western Ghats, India. Ann. Microbiol. 65, 785-797 (2015).

18. Trias-Blasi, A. \& Vorontsova, A. Botany: Plant identification is key to conservation. Nature 521, 161 (2015).

19. SCBD COP-10 Decision X/2 Secretariat of the Convention on Biological Diversity (2010).

20. Mishra, P. et al. DNA barcoding: an efficient tool to overcome authentication challenges in the herbal market. Plant Biotech. J. 14, 8-21 (2016).

21. Wilson, K. H. Molecular biology as a tool for taxonomy. Clin. Infect. Dis. 20(Suppl), 192-208 (1995).

22. Hebert, P. D. N., Cywinska, A., Ball, S. L. \& deWaard, J. R. Biological identifications through DNA barcodes. Philos Trans. R. Soc. Lond. B Biol. Sci. 270, 313-321 (2003a).

23. Hebert, P. D. N., Ratnasingham, S. \& de Ward, J. R. Barcoding animal life: cytochrome c oxidase subunit 1 divergences among closely related species. Philos Trans. R. Soc. Lond. B Biol. Sci. 270, S96-S99 (2003b).

24. Hollingsworth, P. M., Graham, S. W. \& Little, D. P. Choosing and using a plant DNA barcode. PLoS ONE 6, e19254 (2011).

25. Kress, W. J., Wurdack, K. J., Zimmer, E. A., Weigt, L. A. \& Janzen, D. H. Use of DNA barcodes to identify flowering plants. Proc. Natl. Acad. Sci. USA 102, 8369-8374 (2005).

26. Ford, C. S. et al. Selection of candidate DNA barcoding regions for use on land plants. Bot. J. Linn. Soc. 159, 1-11 (2009).

27. Fazekas, A. J. et al. Multiple multilocus DNA barcodes from the plastid genome discriminate plant species equally well. PLoS ONE 3, e2802 (2008).

28. Newmaster, S. G., Fazekas, A. J., Steeves, R. A. D. \& Janovec, J. Testing candidate plant barcode regions in the Myristicaceae. Mol. Ecol. Resour. 8, 480-490 (2008).

29. CBOL Plant Working Group, A. DNA barcode for land plants. Proc. Natl. Acad. Sci. USA 106, 12794-12797 (2009).

30. Kress, W. J. \& Erickson, D. L. A two-locus global DNA barcode for land plants: the coding rbcL gene complements the non-coding trnH-psbA spacer region. PLoS ONE 2, e508 (2007).

31. Hollingsworth, M. L. et al. Selecting barcoding loci for plants: Evaluation of seven candidate loci with species-level sampling in three divergent groups of land plants. Mol. Ecol. Resour. 9, 439-457 (2009).

32. Yao, H. et al. Use of ITS2 region as the universal DNA barcode for plants and animals. PLoS ONE 5, e13102 (2010).

33. Li, D. Z. et al. Comparative analysis of a large dataset indicates that internal transcribed spacer (ITS) should be incorporated into the core barcode for seed plants. Proc. Natl. Acad. Sci. USA 108, 19641-19646 (2011).

34. Newmaster, S. G., Fazekas, A. J. \& Ragupathy, S. DNA barcoding in land plants: evaluation of rbcL in a multigene tiered approach. Can. J. Bot. 84, 335-341 (2006).

35. Chase, M. W. et al. A proposal for a standardised protocol to barcode all land plants. Taxon 56, 295-299 (2007).

36. Mishra, P. et al. Evaluation of single and multilocus DNA barcodes towards species delineation in complex tree genus Terminalia. Plos One 12, e0182836 (2017).

37. Techen, N., Praveen, I., Pan, Z. \& Khan, I. A. DNA barcoding of medicinal plant material for identification. Current Opinion in Biotechnology 25, 103-110 (2014).

38. Li, X. et al. Plant DNA barcoding: from gene to genome. Biological Reviews 90, 157-166 (2015).

39. Xin, T. et al. Survey of commercial Rhodiola products revealed species diversity and potential safety issues. Sci. Rep. 5, 8337 (2015).

40. Baldwin, B. G. et al. The ITS region of nuclear ribosomal DNA: a valuable source of evidence on angiosperm phylogeny. Ann. Mo. Bot. Gard. 82, 247-277 (1995).

41. Giudicelli, G. C., Mäder, G. \& Freitas, de. L. B. Efficiency of ITS Sequences for DNA barcoding in Passiflora (Passifloraceae). I.J.M.S. 16, 7289-7303 (2015)

42. Aubriot, X., Lowry, P. P., Cruaud, C., Couloux, A. \& Haevermans, T. DNA barcoding in a biodiversity hotspot: potential value for the identification of Malagasy Euphorbia L listed in CITES Appendices I and II. Mol. Ecol. Resour. 13, 57-65 (2013).

43. Kim, W. J. et al. Molecular identification and phylogenetic analysis of important medicinal plant species in Genus Paeonia based on rDNA-ITS, matK, and rbcL DNA barcode sequences. Genet. Mol. Res. 15, https://doi.org/10.4238/gmr.15038472 (2016).

44. Di, H. et al. Interspecific phylogenetic relationships within Genus Melilotus based on nuclear and chloroplast DNA. PLoS ONE 10, e0132596 (2015).

45. Soltis, E. D. \& Soltis, P. S. Contributions of plant molecular systematics to studies of molecular evolution. Plant Mol. Biol. 42, 45-75 (2000).

46. Little, D. P. \& Stevenson, D. W. A comparison of algorithms for the identification of specimens using DNA barcodes: examples from gymnosperms. Cladistics 23, 1-21 (2007).

47. Austerlitz, F. et al. DNA barcode analysis: a comparison of phylogenetic and statistical classification methods. BMC Bioinformatics 10, S10 (2009).

48. Casiraghi, M., Labra, M., Ferri, E., Galimberti, A. \& deMattia, F. DNA barcoding: theoretical aspects and practical applications In: Nimis, P. L. \& Lebbe, R. V. eds Tools for Identifying Biodiversity: Progress and Problems. EUT Publishers, 269-273 (2010).

49. Sandionigi, A. et al. Analytical approaches for DNA barcoding data-how to find a way for plants? Plant Biosyst. 146, 805-813 (2012).

50. Alves, T. L. S., Chauveau, O., Eggers, L. \& Souza-Chies, T. T. D. Species discrimination in Sisyrinchium (Iridaceae): assessment of DNA barcodes in a taxonomically challenging genus. Mol. Ecol. Resour. 14, 324-335 (2014).

51. Meier, R., Shiyang, K., Vaidya, G. \& Ng, P. K. DNA barcoding and taxonomy in Diptera: a tale of high intraspecific variability and low identification success. Syst. Biol. 55, 715-728 (2006). 
52. Tateno, Y. I., Takezaki, N. \& Nei, M. Relative efficiencies of the maximum-likelihood, neighbor-joining, and maximum-parsimony methods when substitution rate varies with site. Mol. Biol. Evol. 11, 261-77 (1994).

53. Chen, S. et al. Validation of the ITS2 region as a novel DNA barcode for identifying medicinal plant species. PLoS One 5, e8613 (2010).

54. Holtken, A. M. et al. Development of DNA-based methods to identify CITES-protected timber species: a case study in the Meliaceae family. Holzforschung 66, 97-104 (2012).

55. Deguilloux, M. F., Pemonge, M. H. \& Petit, R. J. Novel perspectives in wood certification and forensics: dry wood as a source of DNA. Proc. R. Soc. Lond. B Biol. Sci. 269, 1039-46 (2002).

56. Ogden, R. et al. SNP-based method for the genetic identification of ramin Gonostylus spp. timber and products: applied research meeting CITES enforcement needs. Endang. Species Res. 9, 255-61 (2008).

57. Khanuja, S. P. S., Shasany, A. K., Darokar, M. P. \& Kumar, S. Rapid isolation of DNA from dry and fresh samples of plants producing large amounts of secondary metabolites and essential oils. Plant Mol. Biol. Rep. 17, 1-7 (1999).

58. Ratnasingham, S. \& Hebert, P. D. N. BOLD: the Barcode of Life Data System (www.barcodinglife.org) Mol. Ecol. Notes. 7, 355-364 (2007).

59. Zhang, Z., Schwartz, S., Wagner, L. \& Miller, W. A greedy algorithm for aligning DNA sequences. J. Comp. Biol. 7, 203-14 (2000).

60. Morgulis, A. et al. Database indexing for production: Mega BLAST Searches. Bioinformatics 24, 1757-1764 (2008).

61. Hall, T. A. BioEdit: a user-friendly biological sequence alignment editor and analysis program for Windows 95/98/NT. Nucleic Acids Symposium Series 41, 95-98 (1999).

62. Tamura, K., Stecher, G., Peterson, D., Filipski, A. \& Kumar, S. MEGA6: Molecular evolutionary genetics analysis version 6.0. Mol. Biol. Evol. 30, 2725-2729 (2013).

63. Kimura, M. A simple method for estimating evolutionary rates of base substitutions through comparative studies of nucleotide sequences. J. Mol. Evol. 16, 111-120 (1980).

64. Meyer, C. P. \& Paulay, G. DNA barcoding: error rates based on comprehensive sampling. PLoS Biol. 3, e422 (2005).

65. Wiemers, M. \& Fiedler, K. Does the DNA barcoding gap exist? A case study in blue butterflies (Lepidoptera: lycaenidae). Front. Zool. 4, 8 (2007).

66. Bertolazzi, P., Felici, G. \& Weitschek, E. Learning to classify species with barcodes. BMC Bioinformatics 14, S7 (2009).

67. Weitschek, E., Van Velzen, R., Felici, G. \& Bertolazzi, P. BLOG 20: a software system for character-based species classification with DNA Barcode sequences What it does, how to use it. Mol. Ecol. Resour. 13, 1043-6 (2013).

68. Swofford, D. L. PAUP*: Phylogenetic analysis using parsimony (* and other methods), version $40 \mathrm{~b} 10$ Sunderland: Sinauer. http:// paup.sc.fsu.edu/ (2003).

69. Felsenstein, J. Phylogenies from molecular sequences: inference and reliability. Annu. Rev. Genet 22, 521-565 (1988).

70. Cuenoud, P. et al. Molecular phylogenetics of Caryophyllales based on nuclear $18 \mathrm{~S}$ rDNA and plastid $r b c L$, atpB, and matK DNA sequences. Am. J. Bot. 89, 132-144 (2009).

71. Zheng, S., Jiang, X., Wu, L., Wang, Z. \& Huang, L. Chemical and genetic discrimination of Cistanches herba based on UPLC-QTOF/ MS and DNA barcoding. PLoS ONE 9, e98061 (2014).

\section{Acknowledgements}

The authors are grateful to Director, CSIR-CIMAP, Lucknow, for his encouragement and providing laboratory facilities for the study. The financial support from the Council of Scientific and Industrial Research (CSIR), New Delhi, India through the XII ${ }^{\text {th }}$ FYP project Biopros-PR (BSC-0106) and ChemBio (BSC-0203) is gratefully acknowledged.

\section{Author Contributions}

P.M., A.K.S. and V.S. contributed to the study design. A.K., S.G., K.R. and V.S. performed the field study with proper permissions and contributed the plant samples. P.M. and A.K. conducted the experiments. P.M. performed the data integration, sequence analysis and wrote the main manuscript text. K.R. and P.M. contributed to the figure S1. A.K.S., A.S. and V.S. critically revised the manuscript. All authors read and approved the final manuscript.

\section{Additional Information}

Supplementary information accompanies this paper at https://doi.org/10.1038/s41598-017-14887-8.

Competing Interests: The authors declare that they have no competing interests.

Publisher's note: Springer Nature remains neutral with regard to jurisdictional claims in published maps and institutional affiliations.

Open Access This article is licensed under a Creative Commons Attribution 4.0 International License, which permits use, sharing, adaptation, distribution and reproduction in any medium or format, as long as you give appropriate credit to the original author(s) and the source, provide a link to the Creative Commons license, and indicate if changes were made. The images or other third party material in this article are included in the article's Creative Commons license, unless indicated otherwise in a credit line to the material. If material is not included in the article's Creative Commons license and your intended use is not permitted by statutory regulation or exceeds the permitted use, you will need to obtain permission directly from the copyright holder. To view a copy of this license, visit http://creativecommons.org/licenses/by/4.0/.

(C) The Author(s) 2017 